\title{
Parent-adolescent agreement in reported moderate-to-vigorous intensity physical activity during the COVID-19 pandemic
}

\author{
Jason M. Nagata ${ }^{*}$, Catherine A. Cortez ${ }^{2}$, Puja lyer ${ }^{1}$, Erin E. Dooley ${ }^{3}$, Kyle T. Ganson ${ }^{4}$, Amy A. Conroy ${ }^{5}$ and \\ Kelley Pettee Gabriel ${ }^{3}$
}

\begin{abstract}
Purpose: To describe the agreement between parent- and adolescent- reports of adolescent moderate-to-vigorous intensity physical activity (MVPA) and to determine sociodemographic factors associated with MVPA reporting differences during the COVID-19 pandemic.

Methods: We analyzed data collected in May 2020 from the Adolescent Brain Cognitive Development Study (ABCD, $N=4841$ ), a U.S. prospective cohort study. We quantified past weekly adolescent MVPA levels as reported by the parent and adolescent (referent). Intra-class correlation coefficients (ICC) and Bland-Altman plots were used to examine the degree of agreement between parent- and adolescent- reports.

Results: When quantifying adolescent MVPA during the same recall period, median ( $p 25, p 75)$ MVPA (h.wk. ${ }^{-1}$ ) was $2.17(0.00,6.00)$ as reported by adolescents and $1.52(0.29,4.75)$ by parents with a mean difference of 4.89 . Statistically significant differences in reports of MVPA were found in households with income $>\$ 75,000$ : on average, adolescents reported higher MVPA levels than their parents. Bland-Altman plots illustrated that, among adolescents reporting no or little MVPA, there was higher parent-adolescent agreement. However, among adolescents reporting high levels of MVPA, there was less agreement between the parent- and adolescent- reports.

Conclusions: Despite more time spent together at home during the pandemic, there was generally low agreement between parent- and adolescent- reports of adolescent MVPA. Future research could examine parent-adolescent agreement of MVPA within the context of device-based measures (e.g., accelerometers), determine reasons for differences in parent-adolescent reporting of MVPA, and inform interventions for improved parental involvement and monitoring of MVPA.
\end{abstract}

Keywords: Adolescents, Parents, Physical activity, Moderate-to-vigorous intensity physical activity, Physical activity measurement, COVID-19

\footnotetext{
*Correspondence: jason.nagata@ucsf.edu

1 Department of Pediatrics, University of California, San Francisco, 550

16th Street, 4th Floor, Box 0110, San Francisco, California 94158, USA

Full list of author information is available at the end of the article
}

\begin{abstract}
Introduction
Among children and adolescents, moderate-to-vigorous intensity physical activity (MVPA; e.g., running, swimming, or bicycling) is associated with a myriad of health benefits, including lower risk of obesity, higher bone mass, and improved cardiometabolic health $[1,2]$. Given the known benefits to child and adolescent health, the U.S. Department of Health and Human Services
\end{abstract} original author(s) and the source, provide a link to the Creative Commons licence, and indicate if changes were made. The images or other third party material in this article are included in the article's Creative Commons licence, unless indicated otherwise in a credit line to the material. If material is not included in the article's Creative Commons licence and your intended use is not permitted by statutory regulation or exceeds the permitted use, you will need to obtain permission directly from the copyright holder. To view a copy of this licence, visit http://creativecommons.org/licenses/by/4.0/. The Creative Commons Public Domain Dedication waiver (http://creativeco mmons.org/publicdomain/zero/1.0/) applies to the data made available in this article, unless otherwise stated in a credit line to the data. 
recommends that school-aged youth 6-17years of age participate in at least $60 \mathrm{~min}$ of MVPA every day [3].

Population-based studies with youth often use selfreport-based methods to assess MVPA and estimate the prevalence of those meeting physical activity guidelines. Report-based MVPA measures are generally simple to administer and inexpensive, and thus are commonly used $[4,5]$. However, report-based MVPA measures are reliant on memories that are prone to fallicies in retrieval due to decay over time or interference of other memories. Memories may also be filtered by perceptions and biases. Specifically, participant-reported MVPA may be affected by recall [6] and social desirability bias: youth often overestimate their intensity and time spent on MVPA [7]. Use of a proxy respondent varies based on the age of the child with research suggesting that children aged 10 years and older are developmentally mature enough to provide reliable and valid estimates of MVPA $[4,8-10]$. To obtain physical activity estimates in younger children, reports from a parent or adult (e.g., teacher) have been used to estimate the child's MVPA. Prior studies have reported on the agreement and correlation between parent and child accounts of children's physical activity levels; however, a majority were in children under 10 years of age $[4,8,10-12]$. Notably, levels of agreement between parent- versus child- reports of physical activity may vary between different populations dependent on the child's age group. To obtain physical activity estimates in younger children, reports from a parent or adult (e.g., teacher) are relied upon to estimate the child's MVPA. The literature has shown that parent report proxies are typically used for younger children's activity levels [13-16], while older children typically self-report their own physical activity levels [17-25]. Findings regarding agreement between parent- and child- reports of physical activities have ranged from low to slight to fair in pediatric populations up until age $14[12,16,26,27]$. Prior studies have suggested that using a self-report may be more reliable than parental proxy report in children over the age of 10 [27].

The sociodemographic correlates of discrepancies of parent- and youth- reported physical activity identified in the literature include parent gender [16], youth weight status [12, 16], youth age [28], youth gender [12], family cohesion [28], and family socioeconomic status [12]. These differences may also stem from the fact that parental monitoring of youth physical activity is limited during the time that youth spend at school and parents spend at work $[29,30]$.

With the onset of the COVID-19 pandemic, social distancing, school closures, and changes in access to community parks and recreational facilities have changed the way in which adolescents participate in MVPA and have led to more time spent at home [31, 32]. Although previous studies reported low agreement in MVPA between parents and adolescents [12, 16, 26, 27], the dyadic agreement between parents and adolescents may have improved during the pandemic due to increased time spent at home together as a result of stay-at-home orders, school and business closures, and travel restrictions [31, 32]. Conversely, with the cancellation of regular routines such as sports team practices and training, competitions, and in-person physical education classes [33], there may have been greater difficulty to recall time spent on MVPA given these activities are often more structured than recreational activity. The stay-at-home orders and other changes during the COVID-19 pandemic [32] allowed for a natural experiment to examine the parental proxy measures of adolescent MVPA in a unique time during which adolescents and their parents may have been in closer quarters with one another and there may have been limited sanctioned opportunities for physical activities.

The present study aims to describe the differences and agreement between parental reports of adolescent physical activity and adolescent self-reports of MVPA. We hypothesize that there will be some agreement between parent- and adolescent- reports of adolescent physical activity during the COVID-19 pandemic given the increased number of hours families spend together and due to fewer MVPA opportunities during the COVID19 pandemic. Second, we aim to determine sociodemographic correlates of the parent-adolescent dyad physical activity reporting differences. We hypothesized that factors such as adolescent sex, race/ethnicity, education, and household income will be associated with differences in parent and adolescent physical activity reports.

\section{Methods}

\section{Study population}

We analyzed data from the Adolescent Brain Cognitive Development (ABCD) Study, a national (U.S.) prospective cohort study of brain development and health among 11,875 adolescents. The University of California, San Diego provided centralized institutional review board (IRB) approval and each participating site received local IRB approval. Written informed consent and assent were obtained from the parent and adolescent, respectively, to participate in the ABCD Study. Analyses included data from the ABCD Study COVID Rapid Response Research (RRR) Survey 1 (sent between May 16-22, 2020). During this time, almost all states had closed or limited operation of gyms and more than half of states closed all nonessential businesses, although policies varied by U.S. state and counties and cities within these states [32]. Participant pairs were excluded from the analysis if they 
had completed the COVID RRR surveys out of order or had missing data for parent or adolescent sociodemographic characteristics and reported MVPA, resulting in an analytic sample of 4841 participants.

\section{Measures \\ Sociodemographic characteristics}

Parents were asked to respond to the following sociodemographic items in relation to their adolescent: adolescent sex (male or female) and adolescent race/ethnicity (White, Latinx/Hispanic, Black, Asian, Native American, other). Additional characteristics included household income (less than $\$ 75,000$ and $\$ 75,000$ and greater, as this approximated the median household income in the U.S.) and highest parent education (high school or less versus college education or more).

\section{Moderate-to-vigorous intensity physical activity (MVPA)}

Both parents and adolescents reported daily duration (hours and minutes) and frequency (days per week) the adolescent spent participating in MVPA during the past week in the COVID RRR Survey (see Supplemental Appendix). These questions were adapted from the Youth Risk Behavior Survey (YRBS) [34, 35] and the International Physical Activity Questionnaire (IPAQ) Short F form [36, 37] and included prompts such as running, aerobics, or bicycling. Continuous MVPA estimates were computed as the product of reported duration $\left(\mathrm{h} \cdot \mathrm{d}^{-1}\right)$ and frequency $\left(\mathrm{d} \cdot \mathrm{wk} \cdot{ }^{-1}\right)$ and expressed as $\mathrm{h} \cdot \mathrm{wk} \cdot{ }^{-1}$. Given the age of the adolescents ( $>10$ years), we used the adolescent self-report as the referent [4, 8-10]. Differences in parent- and adolescent-reported MVPA (h.wk. ${ }^{-1}$ ) were determined by subtracting parent-reported MVPA from adolescent-reported MVPA (h.wk. $\left.{ }^{-1}\right)$.

\section{Statistical analyses}

The Winsorization method was applied at the 99.5th percentile to minimize the impact of extreme values that were not plausible estimates of weekly MVPA [38]. Extreme values were recoded to the 99.5th percentile value within the respective distributions of parent- and adolescent- reported MVPA.

Sociodemographic characteristics were summarized using descriptive statistics, including measures of central tendency and variability for continuous variables and frequency and proportions for categorical variables. To assess the correlation between parent- and adolescent- reported MVPA, we computed weighted intraclass correlation coefficients (ICCs), which assesses correlation while accounting for within-dyad differences undetected by the Pearson's correlation method. Paired t-tests were then used to determine differences between parent- and adolescent- reported MVPA [39]. Using established ICC cutoff values, we considered poor, fair, moderate, good, and very good agreement to have an ICC less than 0.2 , between 0.2 and 0.4 , between 0.4 and 0.6 , between 0.6 and 0.8 , and between 0.8 and 1 , respectively [40].

Unadjusted parent-reports of MVPA, adolescentreports of MVPA, and differences between parent- and adolescent- reports $\left(\mathrm{h} \cdot \mathrm{wk} .^{-1}\right)$ were further summarized by sex, race/ethnicity, parent education, and household income. P-values were assessed using Wilcoxon Rank Sum or Kruskal-Wallis tests to determine if parent- and adolescent- reported median MVPA differed within groups of each sociodemographic characteristics. Data was weighted using propensity weights from the $A B C D$ Study to approximate the American Community Survey by the U.S. Census [41].

To supplement ICC analyses, the Bland-Altman method was used to visualize agreement in parent- and adolescent- reported MVPA (h.wk. ${ }^{-1}$ ) by plotting parentadolescent difference scores (vertical axis) by the median MVPA values of each parent-adolescent dyad (horizontal axis) [42]. Adolescent- reported MVPA was chosen as the criterion variable, given prior research suggesting that this age group is cognitively able to provide consistent survey responses [27]. Since we are not assuming a normal distribution of parent-adolescent difference scores, limits of agreement (LOA) were estimated using the 2.5th and 97.5th percentile values of the distribution of parent-adolescent difference scores. The average bias was estimated by the median value of the distribution of parent-adolescent difference scores [43]. Data analysis was performed using Stata 15.1 and RStudio v 1.3.1093.

\section{Results}

In this sample, adolescents were aged 10-14years old (mean $12.5 \pm 0.9$ ). Other sample sociodemographic characteristics were as follows: $50.0 \%$ were female; $38.9 \%$ were of racial/ethnic minority background; $10.0 \%$ had a parent with a high school education or less; $33.2 \%$ were in households earning less than $\$ 75,000$ per year (Table 1).

Table 2 presents adolescent- reported MVPA, parentreported MVPA, and parent-adolescent absolute difference scores by hours per day $\left(h \cdot d^{-1}\right)$, days per week $\left(\mathrm{d} \cdot \mathrm{wk} \cdot{ }^{-1}\right)$, and hours per week $\left(\mathrm{h} \cdot \mathrm{wk} \cdot{ }^{-1}\right)$. Adolescents reported engaging in a median of 2.17 [p25, p75 (0.00, 6.00)] hours of MVPA per week compared to $1.52(0.29$, 4.75) hours reported by their parents. Significant dyadic differences were found among each measure of MVPA, with absolute mean differences in parent- and adolescent- reports of $1.15 \mathrm{~h} \cdot \mathrm{d}^{-1}$ (95\% CI 1.08, 1.21), 1.68 d.wk. ${ }^{-1}$ (95\% CI 1.63, 1.72), and $4.89 \mathrm{~h} \cdot \mathrm{wk} .^{-1}$ (95\% CI 4.64, 5.15). Within-dyadic MVPA reports from parents 
Table 1 Sociodemographic characteristics of 4481 participants in the Adolescent Brain Cognitive Development (ABCD) Study, May 2020

\begin{tabular}{ll}
\hline Sociodemographic characteristics & Percent \\
\hline Adolescent characteristics & \\
Sex & \\
$\quad$ Female & $50.0 \%$ \\
Male & $50.0 \%$ \\
Race/ethnicity & \\
White & $61.1 \%$ \\
Latino / Hispanic & $14.7 \%$ \\
Black & $12.7 \%$ \\
Asian & $7.8 \%$ \\
Native American & $2.8 \%$ \\
Other & $1.0 \%$ \\
Parent characteristics & \\
Education & \\
College education or more & $90.0 \%$ \\
High school education or less & $10.0 \%$ \\
Household income & \\
Less than $\$ 25,000$ & $8.4 \%$ \\
\$25,000 through $\$ 49,999$ & $11.3 \%$ \\
\$50,000 through $\$ 74,999$ & $13.5 \%$ \\
\$75,000 through $\$ 99,999$ & $18.6 \%$ \\
\$100,000 through $\$ 199,999$ & $35.4 \%$ \\
\$200,000 and greater & $12.9 \%$ \\
\hline
\end{tabular}

Propensity weights from the Adolescent Brain Cognitive Development Study were applied based on the American Community Survey from the US Census

and adolescents, correlations were poor to moderate among each duration assessment of MVPA (all $p$-values were $<0.001$ ), with ICCs ranging from 0.19 to 0.48 .

A Bland-Altman plot (Fig. 1) further illustrated levels of within-dyad agreement between adolescent and parent-reported MVPA (h.wk. $\left.{ }^{-1}\right)$, revealing that the level of agreement between individual parent-adolescent dyads varied with a range of difference scores between -38.5 to $83.86 \mathrm{~h}$ per week. Difference scores were located closer to the line of perfect agreement when average reported MVPA within dyads was closer to $0 \mathrm{~h}$ per week. Based on the calculated lower and upper bounds of agreement, 95\% percent of differences in MVPA reports were expected to lie between -12.0 and $26.1 \mathrm{~h}$ per week. Therefore, overall agreement was found with only 241 of 4841 (4.8\%) of points lying outside the $95 \%$ interval. Sensitivity analyses stratified by sex, race, and income are shown in the Supplemental Appendix.

Table 3 summarizes parent-adolescent MVPA difference scores by sociodemographic characteristics. Significant differences in parent-adolescent MVPA by sociodemographic characteristics were found for parentadolescent dyads by household income, with high income households having higher differences in parent-adolescent reports (difference score $=0.36[\mathrm{p} 25, \mathrm{p} 75(-1.19$, $3.04 \mathrm{~h} \cdot \mathrm{wk}^{-1}$ )]) compared to low-income households (difference score $\left.=0.00\left[\mathrm{p} 25, \mathrm{p} 75\left(-1.15,2.42 \mathrm{~h} \cdot \mathrm{wk} .^{-1}\right)\right]\right)$. No significant differences in median MVPA hours per week within sex, race/ethnicity, or parent education level were found in this sample.

\section{Discussion}

To our knowledge, this is the first large, national study examining adolescent- and parent- reports of adolescent MVPA in the U.S. While parent and/or adult proxies are commonly used in younger children (aged < 10years), the addition of the COVID RRR Survey to the ABCD study provided the novel opportunity to evaluate this methodological approach for use in adolescents during COVID-19 pandemic, when stay-at-home orders provided more opportunities for time with family members. We describe discrepancies between parent- and adolescent- reported physical activity, while also exploring reporting differences by several sociodemographic factors. We found that if an adolescent had no or little MVPA, the parent was generally accurate in reporting that their child was non-active. However, if the adolescent was active, particularly with very high levels of MVPA, there was less agreement between the parent's and youth's report. When examining sociodemographic factors associated with discrepancies in reported MVPA, there was a greater difference among MVPA parent and youth reporting among adolescents with higher MVPA, particularly in families with income $>\$ 75,000$.

The finding that there was greater parent-adolescent agreement with lower levels of MVPA supports prior

Table 2 Parent- vs. adolescent- reported moderate-to-vigorous intensity physical activity (MVPA), ABCD Study, May 2020 (N=4481)

\begin{tabular}{lllllll}
\hline & $\begin{array}{l}\text { Adolescent } \\
\text { Median (p25, p75) }\end{array}$ & $\begin{array}{l}\text { Parent } \\
\text { Median (p25, p75) }\end{array}$ & $\begin{array}{l}\text { Difference } \\
\text { Mean (95\% Cl) }\end{array}$ & t & p & ICC (95\% CI) \\
\hline Hours/day & $1.00(0.00,1.67)$ & $0.50(0.19,1.07)$ & $1.15(1.08,1.21)$ & 34.85 & $<\mathbf{0 . 0 0 1}$ & $0.19(0.15,0.23)$ \\
Days/week & $2.00(1.00,4.00)$ & $3.00(2.00,5.00)$ & $1.68(1.63,1.72)$ & 72.08 & $<\mathbf{0 . 0 0 1}$ & $0.48(0.45,0.50)$ \\
Hours/week & $2.17(0.00,6.00)$ & $1.52(0.29,4.75)$ & $4.89(4.64,5.15)$ & 37.11 & $<\mathbf{0 . 0 0 1}$ & $0.28(0.24,0.32)$ \\
\hline
\end{tabular}




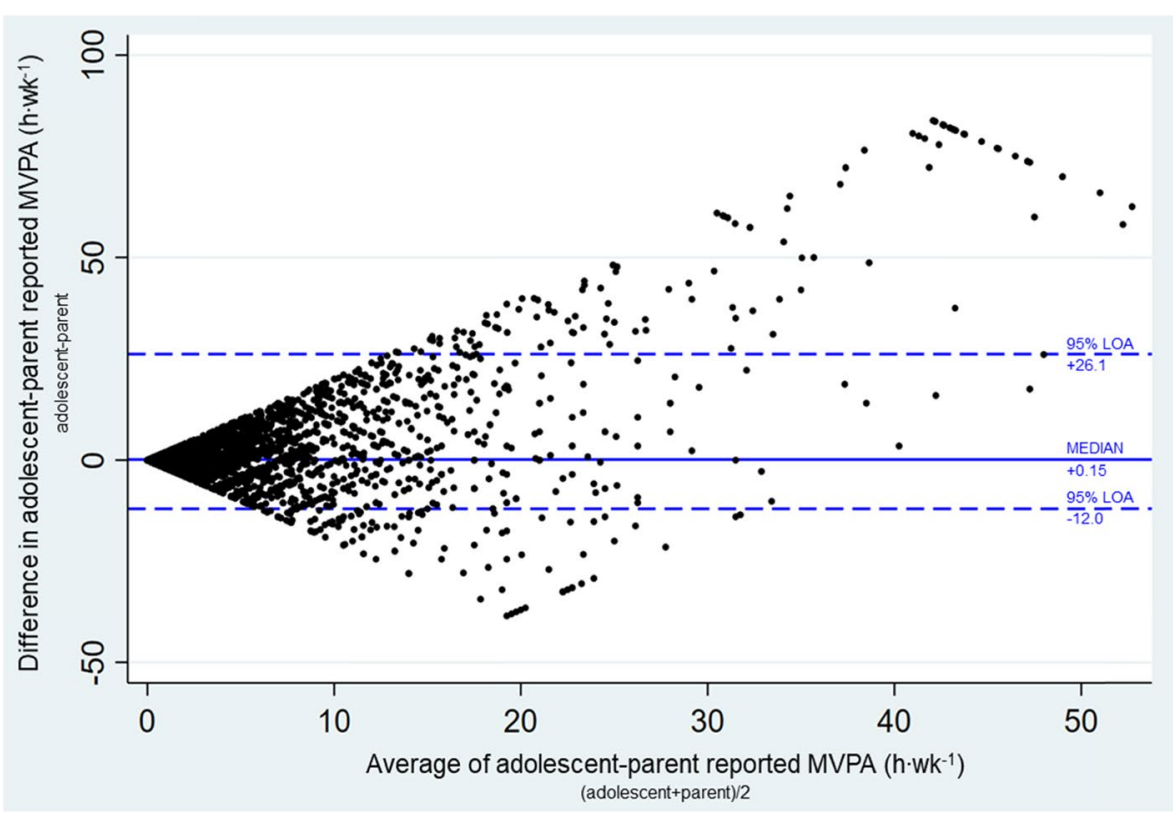

Fig. 1 Bland-Altman Plot for agreement between adolescent-parent moderate-to-vigorous intensity physical (MVPA) activity reports. LOA=limits of agreement

Table 3 Summary of difference scores in parent- and adolescent- reported moderate-to-vigorous intensity physical activity (MVPA) during the COVID-19 pandemic by sociodemographic characteristics in the Adolescent Brain Cognitive Development (ABCD) Study, May 2020, $(\mathrm{N}=4481)$

\begin{tabular}{|c|c|c|c|c|}
\hline \multirow[b]{3}{*}{ Sociodemographic characteristics } & \multicolumn{3}{|l|}{ Hours of MVPA/week } & \multirow{3}{*}{$\mathrm{p}$} \\
\hline & Adolescent reported & Parent reported & Difference score & \\
\hline & Median (p25, p75) & Median (p25, p75) & Median (p25, p75) & \\
\hline \multicolumn{5}{|l|}{ Adolescent characteristics } \\
\hline Sex & & & & $0.09^{\mathrm{a}}$ \\
\hline Female & $2.01(0.00,6.00)$ & $1.29(0.28,4.15)$ & $0.19(-0.86,2.67)$ & \\
\hline Male & $2.33(0.00,6.65)$ & $1.92(0.42,5.35)$ & $0.00(-1.29,3.00)$ & \\
\hline Race/ethnicity & & & & $0.05^{b}$ \\
\hline White & $2.68(0.50,6.99)$ & $1.92(0.58,5.35)$ & $0.21(-1.28,2.96)$ & \\
\hline Latino / Hispanic & $1.50(0.00,5.01)$ & $1.29(0.17,3.55)$ & $0.00(-0.96,2.42)$ & \\
\hline Black & $2.00(0.00,6.00)$ & $1.29(0.14,5.13)$ & $0.00(-1.05,2.09)$ & \\
\hline Asian & $2.31(0.66,5.34)$ & $1.52(0.38,3.55)$ & $0.42(-1.00,2.71)$ & \\
\hline Native American & $1.50(0.00,4.00)$ & $1.14(0.14,3.55)$ & $-0.14(-1.08,1.92)$ & \\
\hline Other & $3.00(0.00,7.50)$ & $0.66(0.14,3.44)$ & $0.60(-0.21,4.74)$ & \\
\hline \multicolumn{5}{|l|}{ Parent characteristics } \\
\hline Highest parent education & & & & $1.00^{\mathrm{a}}$ \\
\hline College education or more & $2.33(0.17,6.00)$ & $1.80(0.38,5.16)$ & $0.09(-1.19,2.78)$ & \\
\hline High school education or less & $1.67(0.00,6.00)$ & $1.14(0.14,3.55)$ & $0.00(-0.66,3.00)$ & \\
\hline Household income & & & & $0.03^{\mathrm{a}}$ \\
\hline$\$ 75,000$ and greater & $3.00(0.66,7.00)$ & $1.92(0.58,5.35)$ & $0.36(-1.19,3.04)$ & \\
\hline Less than $\$ 75,000$ & $2.00(0.00,5.01)$ & $1.29(0.17,3.80)$ & $0.00(-1.15,2.42)$ & \\
\hline
\end{tabular}

\footnotetext{
${ }^{a}$ Wilcoxon Rank Sum test
}

${ }^{\mathrm{b}}$ Kruskal-Wallis test 
research results that indicate higher agreement on reporting of sports and outdoor activities among the lowest quartiles of reported activity [26]. In the context of the pandemic, non-active adolescents may be more likely to be home and engage in sedentary activities, such as recreational screen time, that can be better monitored by parents. It is also possible that there may be less activities to recall for both non-active adolescents and their parents, increasing the agreement of both reports (i.e., less measurement error). We initially hypothesized that there would be moderate to high parent-adolescent agreement in MVPA reporting during the pandemic for these reasons. Prior studies examining parent-adolescent agreement in physical activity among overlapping age groups reported Kappas of 0.11 (low) to 0.41 (fair). Our overall frequency agreement (ICC of 0.28) is within this range; however, the statistics were different (ICC vs Kappa) and the physical activity measure was slightly different (MVPA vs outside play, outdoor activities, leisure sports, organized sports, respectively) $[12,16,26]$.

Conversely, if the adolescent is active, particularly with very high levels of MVPA, there is less agreement between the parent and the adolescent report, similar to previous findings [26]. On the adolescent side, this may be due to cognitive processes related to memory that make it harder to recall physical activity occurrence, frequency, and duration based on the structure of survey questions [44]. On the parent side, this may be due to the parent not knowing what their child is doing, particularly when the child is doing activities outdoors or overtraining. Active adolescents may be doing activities outside of the home with peers, teams, or individually of which parents may not be aware. For example, despite COVID-19 restrictions, some sports teams have maintained outdoor or distanced training routines. Moreover, at high levels of training for sports teams or competition, adolescents may overtrain [45] and may not want their parents to know how much they are training. Similarly, with eating disorders being exacerbated during the COVID-19 pandemic [46], more young people may be at engaging in excess covert exercise as a way to cope [47].

Overall, we found that adolescents reported more MVPA (h.wk. ${ }^{-1}$ ) than parents, similar to previous findings [16]. Adolescents may overestimate their intensity and time spent on MVPA [7]. Our findings also demonstrated greater discrepancies in subgroups with higher MVPA levels, such as adolescents from households with higher income. During the pandemic, adolescents from low-income neighborhoods may have been more affected by restricted access to safe outdoors spaces for MVPA [48], leading to lower MVPA levels and less parentadolescent reporting discrepancies. Conversely, adolescents attending private schools were more likely to have in-person schooling during the pandemic [49] which could have allowed for more MVPA options and a greater parent-adolescent reporting discrepancy due to time away. One prior study of 9-12-year-olds similarly found that children of high socioeconomic status were more likely to report a higher frequency of outside play than their parents compared to children of low socioeconomic status [12]. Although we initially hypothesized that parent monitoring could have been improved due to more time at home from stay-at-home orders [31, 32], parents who are working from home may not have the flexibility to monitor their children while performing work duties and parents who are essential workers continue to go to in person work.

\section{Strengths and limitations}

Strengths of our study stem from the utilization of a large, national adolescent study population with parent-adolescent dyads during the COVID-19 pandemic. Moreover, estimates of the adolescent's MVPA were uniquely obtained from both the adolescent and the parent. However, despite these strengths, there are several limitations to our findings. Our data relies on reported estimates of adolescent MVPA through self-reports and parent reports, which may be subject to social desirability and recall bias. Unfortunately, more objective measures, including direct observation (criterion) or accelerometry were not collected to assess the potential bias of self-reported MVPA estimates, and in the absence of an objective measure, we cannot evaluate whether child- or parent- reports are more accurate. Moreover, there was some loss-to-follow-up and non-responders to the COVID-19 RRR survey administered by the ABCD study, meaning that there is risk for selection bias and limitations on the generalizability of these results. Nonresponders were more likely to be from lower socioeconomic status backgrounds and racial/ethnic minorities, sociodemographic groups with lower average levels of MVPA. Additionally, the cross-sectional nature of this study limits our ability to establish causality, and may not be representative of longitudinal trends in MVPA agreement during the COVID-19 pandemic.

\section{Implications and conclusions}

While most population-based studies of adolescents rely on self-report given their cognitive development [50], the addition of a parent proxy report in the ABCD COVID19 RRR survey provided us the unique opportunity to examine the overall agreement between adolescent- and parent- reports of MVPA during the COVID-19 pandemic. However, we found that discrepancies in parent and adolescent agreement of MVPA persisted even during this time of closer cohabitation. Given the general 
decline in MVPA among adolescents and adults during the pandemic, family activities involving MVPA could both increase MVPA levels and improve agreement and monitoring of MVPA by parents. Schools and athletics programs can also involve parents more in the planning and accommodation of physical education classes or sports teams during the pandemic.

Our findings have implications for clinical and research practices in regards to measuring adolescent physical activity. Given decreases in MVPA during the pandemic [51] and discrepancies in parent-adolescent reporting of MVPA, parents could discuss and encourage MVPA with their adolescents. Pediatricians could consider assessing for and promoting MVPA for adolescents and their parents at primary care visits during the pandemic. These discrepancies also point to the need for research examining parent- and adolescent- reports of MVPA within the context of device-based measures (e.g., accelerometers). This information could be used to refine measures of adolescent MVPA and inform clinical practice given limited time in clinical visits (e.g., focusing on asking the adolescent only about MVPA if their report is more accurate than their parents' report). Further studies could determine reasons for differences in parent-adolescent reporting of MVPA and use this knowledge to inform interventions for improved parental involvement and monitoring of MVPA.

\section{Supplementary Information}

The online version contains supplementary material available at https://doi. org/10.1186/s12889-022-12530-4.

Additional file 1: Supplemental Appendix. Figure S1. Agreement between adolescent-parent MVPA reports among female adolescents. Figure S2. Agreement between adolescent-parent MVPA reports among male adolescents. Figure S3. Agreement between adolescent-parent MVPA reports among non-white adolescents. Figure S4. Agreement between adolescent-parent MVPA reports among white adolescents. Figure S5. Agreement between adolescent-parent MVPA reports in households with income $\$ 75,000+$. Figure S6. Agreement between adolescent-parent MVPA reports in households with income $<\$ 75,000+$.

\section{Acknowledgments}

The authors thank Anthony Kung for editorial assistance. The ABCD Study was supported by the National Institutes of Health and additional federal partners under award numbers U01DA041022, U01DA041025, U01DA041028, U01DA041048, U01DA041089, U01DA041093, U01DA041106, U01DA041117, U01DA041120, U01DA041134, U01DA041148, U01DA041156, U01DA041174, U24DA041123, and U24DA041147. A full list of supporters is available at https://abcdstudy.org/nihcollaborators. A listing of participating sites and a complete listing of the study investigators can be found at https://abcdstudy. org/principal-investigators.html. ABCD consortium investigators designed and implemented the study and/or provided data but did not necessarily participate in the analysis or writing of this report.

\section{Role of the funder/sponsor}

The funders had no role in the design and conduct of the study; collection, management, analysis, and interpretation of the data; preparation, review, or approval of the manuscript; and decision to submit the manuscript for publication.

\section{Authors' contributions}

Dr. Nagata was responsible for the development of the research study design, methods, data cleaning, writing, and supervision. Ms. Cortez was responsible for implementing the methods and analyses with quidance and input from Drs. Nagata and Gabriel, drafted the results section and portions of the methods section, and created the tables and figures. Ms. Iyer, drafted portions of the introduction, methods, and discussion sections of the manuscript. Dr. Dooley and Dr. Conroy critically reviewed the manuscript. Dr. Ganson was responsible for providing manuscript revisions, input on the research design, and contributions to the writing of the overall manuscript. Dr. Gabriel contributed to the conceptualization of the study and provided supervision. All authors had input into the study design, took part in all revisions of the manuscript, and approved the final submitted version.

\section{Funding}

J.M.N. was funded by the National Heart, Lung, and Blood Institute (K08HL159350) and the American Heart Association (CDA34760281).

\section{Availability of data and materials}

Data used in the preparation of this article were obtained from the ABCD Study (https://abcdstudy.org), held in the NIMH Data Archive (NDA). Investigators can apply for data access through the NDA (https://nda.nih.gov/).

\section{Declarations}

Ethics approval and consent to participate

Written informed consent and assent were obtained from the parent/guardian and adolescent, respectively, to participate in the ABCD Study. The University of California, San Diego provided centralized institutional review board (IRB) approval and each participating site received local IRB approval:

- Children's Hospital Los Angeles, Los Angeles, California

- Florida International University, Miami, Florida

- Laureate Institute for Brain Research, Tulsa, Oklahoma

- Medical University of South Carolina, Charleston, South Carolina

- Oregon Health and Science University, Portland, Oregon

- SRI International, Menlo Park, California

- University of California San Diego, San Diego, California

- University of California Los Angeles, Los Angeles, California

- University of Colorado Boulder, Boulder, Colorado

- University of Florida, Gainesville, Florida

- University of Maryland at Baltimore, Baltimore, Maryland

- University of Michigan, Ann Arbor, Michigan

- University of Minnesota, Minneapolis, Minnesota

- University of Pittsburgh, Pittsburgh, Pennsylvania

- University of Rochester, Rochester, New York

- University of Utah, Salt Lake City, Utah

- University of Vermont, Burlington, Vermont

- University of Wisconsin-Milwaukee, Milwaukee, Wisconsin

- Virginia Commonwealth University, Richmond, Virginia

-Washington University in St. Louis, St. Louis, Missouri

- Yale University, New Haven, Connecticut

All methods were carried out in accordance with relevant guidelines and regulations.

\section{Consent for publication}

Not applicable.

\section{Competing interests}

The authors have no conflict to declare.

\section{Author details}

${ }^{1}$ Department of Pediatrics, University of California, San Francisco, 550 16th Street, 4th Floor, Box 0110, San Francisco, California 94158, USA. ${ }^{2}$ Fielding School of Public Health, University of California, Los Angeles, Los Angeles, California, USA. ${ }^{3}$ Department of Epidemiology, University of Alabama at Birmingham, Birmingham, AL, USA. ${ }^{4}$ Factor-Inwentash Faculty of Social Work, University of Toronto, Toronto, Ontario, Canada. ${ }^{5}$ Division of Prevention 
Science, Department of Medicine, University of California, San Francisco, San Francisco, California, USA.

Received: 12 October 2021 Accepted: 4 January 2022 Published online: 16 February 2022

\section{References}

1. 2018 Physical Activity Guidelines Advisory Committee. 2018 physical activity guidelines advisory committee scientific report. Washington, DC: U.S: Department of Health and Human Services; 2018.

2. Janssen I, LeBlanc AG. Systematic review of the health benefits of physical activity and fitness in school-aged children and youth. Int J Behav Nutr Phys Act. 2010;7:1-16.

3. U.S. Department of Health and Human Services. Physical activity guidelines for Americans, 2nd Edition. 2018. https://health.gov/paguidelines/ second-edition/pdf/Physical_Activity_Guidelines_2nd_edition.pdf.

4. Loprinzi PD, Cardinal BJ. Measuring children's physical activity and sedentary behaviors. J Exerc Sci Fit. 2011;9:15-23.

5. Dollman J, Okely AD, Hardy L, Timperio A, Salmon J, Hills AP. A hitchhiker's guide to assessing young people's physical activity: deciding what method to use. J Sci Med Sport. 2009;12:518-25. https://doi.org/10. 1016/J.JSAMS.2008.09.007.

6. Mattocks C, Leary S, Ness A, Deere K, Saunders J, Tilling K, et al. Calibration of an accelerometer during free-living activities in children. Int J Pediatr Obes. 2007;2:218-26.

7. Hussey J, Bell C, Gormley J. The measurement of physical activity in children. 2013;12:52-8. https://doi.org/10.1179/108331907X174989.

8. Sallis JF. Self-report measures of Children's physical activity. J Sch Health. 1991;61:215-9. https://doi.org/10.1111/J.1746-1561.1991.TB06017.X.

9. Baranowski T, Dworkin RJ, Cieslik CJ, Hooks P, Clearman DR, Ray L, et al. Reliability and validity of self report of aerobic activity: family health project. Res Q Exerc Sport. 1984;55:309-17.

10. Sirard JR, Pate RR. Physical Activity Assessment in Children and Adolescents. Sport Med. 2012;31:439-54. https://doi.org/10.2165/00007256200131060-00004.

11. Thorn JE, Delellis N, Chandler JP, Boyd K. Parent and child self-reports of dietary behaviors, physical activity, and screen time. J Pediatr. 2013;162:557-61.

12. Koning M, de Jong A, de Jong E, Visscher TLS, Seidell JC, Renders CM. Agreement between parent and child report of physical activity, sedentary and dietary behaviours in 9-12-year-old children and associations with children's weight status. BMC Psychol. 2018;6:1-11.

13. Graf C, Koch B, Dordel S, Schindler-Marlow S, Icks A, Schüller A, et al. Physical activity, leisure habits and obesity in first-grade children. Eur J Prev Cardiol. 2004;11:284-90.

14. Tremblay MS, Willms JD. Is the Canadian childhood obesity epidemic related to physical inactivity? Int J Obes. 2003;27:1100-5.

15. Janz KF, Levy SM, Burns TL, Torner JC, Willing MC, Warren JJ. Fatness, physical activity, and television viewing in children during the adiposity rebound period: the lowa bone development study. Prev Med (Baltim). 2002;35:563-71.

16. Sithole F, Veugelers PJ. Parent and child reports of children's activity. Health Rep. 2008;19:19-24.

17. Hernández B, Gortmaker SL, Colditz GA, Peterson KE, Laird NM, ParraCabrera S. Association of obesity with physical activity, television programs and other forms of video viewing among children in Mexico City. Int J Obes. 1999:23:845-54.

18. McMurray RG, Harrell JS, Deng S, Bradley CB, Cox LM, Bangdiwala SI. The influence of physical activity, socioeconomic status, and ethnicity on the weight status of adolescents. Obes Res. 2000;8:130-9.

19. Giammattei J, Blix G, Marshak HH, Wollitzer AO, Pettitt DJ. Television watching and soft drink consumption: associations with obesity in 11- to 13-year-old schoolchildren. Arch Pediatr Adolesc Med. 2003;157:882-6.

20. Vandewater EA, Shim MS, Caplovitz AG. Linking obesity and activity level with children's television and video game use. J Adolesc. 2004;27:71-85.

21. Janssen I, Katzmarzyk PT, Boyce WF, Vereecken C, Mulvihill C, Roberts C, et al. Comparison of overweight and obesity prevalence in school-aged youth from 34 countries and their relationships with physical activity and dietary patterns. Obes Rev. 2005;6:123-32.
22. Koezuka N, Koo M, Allison KR, Adlaf EM, Dwyer JJM, Faulkner G, et al. The relationship between sedentary activities and physical inactivity among adolescents: results from the Canadian community health survey. J Adolesc Health. 2006;39:515-22.

23. Dowda M, Ainsworth BE, Addy CL, Saunders R, Riner W. Environmental influences, physical activity, and weight status in 8- to 16-year-olds. Arch Pediatr Adolesc Med. 2001;155:711-7.

24. Janssen I, Katzmarzyk PT, Boyce WF, King MA, Pickett W. Overweight and obesity in Canadian adolescents and their associations with dietary habits and physical activity patterns. J Adolesc Health. 2004;35:360-7.

25. Lowry R, Wechsler H, Galuska DA, Fulton JE, Kann L. Television viewing and its associations with overweight, sedentary lifestyle, and insufficient consumption of fruits and vegetables among US high school students: differences by race, ethnicity, and gender. J Sch Health. 2002;72:413-21.

26. Rah MJ, Mitchell GL, Mutti DO, Zadnik K. Levels of agreement between parents' and children's reports of near work. Ophthalmic Epidemiol. 2002;9:191-203.

27. Pate RR. Physical activity assessment in children and adolescents. Crit Rev Food Sci Nutr. 1993;33:321-6.

28. Gersh E, Richardson LP, Katzman K, Spielvogle H, Arghira AC, Zhou C, et al. Adolescent health risk behaviors: parental concern and concordance between parent and adolescent reports. Acad Pediatr. 2018;18:66-72.

29. Sigmundová D, Sigmund E, Vokáčová J, Kopčáková J. Parent-Child Associations in Pedometer-Determined Physical Activity and Sedentary Behaviour on Weekdays and Weekends in Random Samples of Families in the Czech Republic. Int J Environ Res Public Heal. 2014;11:7163-81. https://doi.org/10.3390/IJERPH110707163.

30. Telford A, Salmon J, Jolley D, Crawford D. Reliability and validity of physical activity questionnaires for children: the Children's leisure activities Study survey (CLASS). Pediatr Exerc Sci. 2004;16:64-78. https://doi.org/10. 1123/PES.16.1.64.

31. Tulchin-Francis K, Stevens W, Gu X, Zhang T, Roberts H, Keller J, et al. The impact of the coronavirus disease 2019 pandemic on physical activity in U.S. children. J Sport Heal Sci. 2021;10:323-32.

32. Gostin LO, Wiley LF. Governmental public health powers during the COVID-19 pandemic: stay-at-home orders, business closures, and travel restrictions. JAMA. 2020;323:2137-8. https://doi.org/10.1001/JAMA.2020. 5460.

33. McGuine TA, Biese KM, Petrovska L, Hetzel SJ, Reardon C, Kliethermes S, et al. Mental health, physical activity, and quality of life of US adolescent athletes during COVID-19-related school closures and sport cancellations: a Study of 13000 athletes. J Athl Train. 2021;56:11-9. https://doi. org/10.4085/1062-6050-0478.20.

34. Centers for Disease Control and Prevention. Youth risk behavior surveillance system - adolescent and school health. Youth risk behavior surveillance system - adolescent and school Health. 2013. https://www.cdc.gov/ healthyyouth/data/yrbs/index.htm.

35. Barch DM, Albaugh MD, Avenevoli S, Chang L, Clark DB, Glantz MD, et al. Demographic, physical and mental health assessments in the adolescent brain and cognitive development study: rationale and description. Dev Cogn Neurosci. 2018;32:55-66.

36. ABCD Study. Release Notes (ABCD Data Release 3.0): COVID Rapid Response Research Survery - First Data Release (Surveys \#1, 2, and 3). 2020. https://nda.nih.gov/study.html?\&id=1225.

37. Lee PH, Macfarlane DJ, Lam T, Stewart SM. Validity of the international physical activity questionnaire short form (IPAQ-SF): A systematic review. Int J Behav Nutr Phys Act. 2011;8:1-11.

38. Garson GD. Testing statistical assumptions. Asheboro: Statistical Publishing Associates; 2012.

39. Fagerland MW. t-tests, non-parametric tests, and large studies - a paradox of statistical practice? BMC Med Res Methodol. 2012;12:1-7. https:// doi.org/10.1186/1471-2288-12-78.

40. JR L, GG K. The measurement of observer agreement for categorical data. Biometrics. 1977;33:159. https://pubmed.ncbi.nlm.nih.gov/843571/. Accessed 10 Sep 2021.

41. Heeringa S, Berglund P. A Guide for Population-based Analysis of the Adolescent Brain Cognitive Development (ABCD) Study Baseline Data. bioRxiv. 2020. https://doi.org/10.1101/2020.02.10.942011.

42. Giavarina D. Understanding Bland Altman analysis. Biochem. Medica. 2015;25:141. https://doi.org/10.11613/BM.2015.015. 
43. Bland JM, Altman DG. Measuring agreement in method comparison studies. Stat Methods Med Res. 1999;8:135-60. https://doi.org/10.1177/ 096228029900800204.

44. Durante R, Ainsworth BE. The recall of physical activity: using a cognitive model of the question-answering process. Med Sci Sports Exerc. 1996;28:1282-91.

45. Winsley R, Matos N. Overtraining and elite young athletes. Med Sport Sci. 2010;56:97-105.

46. Haripersad YV, Kannegiesser-Bailey M, Morton K, Skeldon S, Shipton N, Edwards K, et al. Outbreak of anorexia nervosa admissions during the COVID-19 pandemic. Arch Dis Child. 2021;106:e15.

47. Robertson M, Duffy F, Newman E, Prieto Bravo C, Ates H, Sharpe H. Exploring changes in body image, eating and exercise during the COVID-19 lockdown: a UK survey. Appetite. 2021;159:105062.

48. Mitra R, Moore SA, Gillespie M, Faulkner G, Vanderloo LM, Chulak-Bozzer $\mathrm{T}$, et al. Healthy movement behaviours in children and youth during the COVID-19 pandemic: exploring the role of the neighbourhood environment. Heal Place. 2020;65:102418.

49. Verlenden JV, Pampati S, Rasberry CN, Liddon N, Hertz M, Kilmer G, et al. Association of Children's mode of school instruction with child and parent experiences and well-being during the COVID-19 pandemic COVID experiences survey, United States, October 8-November 13, 2020. MMWR Recomm Reports. 2021;70:369-76.

50. Kowalski KC, PRE C, Donen RM, Honours B. The physical activity questionnaire for older children (PAQ-C) and adolescents (PAQ-A) Manual; 2004.

51. Nagata JM, Cortez CA, Dooley EE, Iyer P, Ganson KT, Pettee Gabriel K. Moderate-to-vigorous intensity physical activity among adolescents in the USA during the COVID-19 pandemic. Prev Med Rep. 2022;25:101685. https://doi.org/10.1016/j.pmedr.2021.101685.

\section{Publisher's Note}

Springer Nature remains neutral with regard to jurisdictional claims in published maps and institutional affiliations.

- fast, convenient online submission

- thorough peer review by experienced researchers in your field

- rapid publication on acceptance

- support for research data, including large and complex data types

- gold Open Access which fosters wider collaboration and increased citations

- maximum visibility for your research: over $100 \mathrm{M}$ website views per year

At BMC, research is always in progress.

Learn more biomedcentral.com/submissions 